Open Access

\title{
Multilevel prognosis of logistics chains in case of uncertainty: information and statistical technologies implementation
}

\author{
Nikita Lukashevich ${ }^{1 *}$, Anna Svirina ${ }^{2}$ and Dmitry Garanin ${ }^{1}$
}

\author{
* Correspondence: \\ lukashevich@spbstu.ru \\ ${ }^{1}$ Peter the Great St. Petersburg \\ Polytechnic University, St. \\ Petersburg, Russia \\ Full list of author information is \\ available at the end of the article
}

\begin{abstract}
Effective, strategic, current and operational management of modern logistics systems requires continuous monitoring and forecasting of their condition in many parameters. Especially these questions are critical in justifying the need for modernization or technical re-equipment of the logistics chains, when the issue for the evaluation of its technical and economic potential is relevant. It can be concluded that there is the need to study the issues of formation of scientifically based logistics solutions. Moreover, by analogy with the systems theory in engineering, it comes to research of the effectiveness of these decisions in conditions of limited, incomplete and often inaccurate information. In general, investment decision on logistics chain modernization is an evaluation of the proposed alternatives for the manager using a set of indicators. It seems to be appropriate to use a method of the potential distribution of probabilities when manager know only the data of relevant characteristics of the logistics chain projects. The application of the method is presented and it is shown that the quantitative estimates calculated by this method are relative and strongly depend on the choice of the base project.
\end{abstract}

Keywords: Logistics chain, Generalized indicator, Bayesian criterion, Shannon entropy, Subjectivity

\section{Introduction}

Effective, strategic, current and operational management of modern logistics systems requires continuous monitoring and forecasting of their condition in many parameters. Especially these questions are critical in justifying the need for modernization or technical re-equipment of the logistics (supply) chains, when the issue for the evaluation of its technical and economic potential is relevant.

It can be concluded that there is the need to study the issues of formation of scientifically based logistics solutions. Moreover, by analogy with the systems theory in engineering, it comes to research of the effectiveness of these decisions in conditions of limited, incomplete and often inaccurate information. In general, the management of the logistics process is based on the adopted corporate policies and involves the coordination of related solutions in various areas (scientific, technical, economic, marketing, sales, etc.). The difficulty of solving this problem is the complexity of combining all these elements to achieve the long-run objective that is to optimize the logistics process in view of the strategic objectives of the organization.

(c) The Author(s). 2018 Open Access This article is distributed under the terms of the Creative Commons Attribution 4.0 International License (http://creativecommons.org/licenses/by/4.0/), which permits unrestricted use, distribution, and reproduction in any medium, provided you give appropriate credit to the original author(s) and the source, provide a link to the Creative Commons license, and indicate if changes were made. 
A decision on the need to modernize the logistics system must be taken in a timely manner and formed with prior, current and forecast information based on adaptability concept with predominant use of «efficiency-cost» criterion. Adaptability means the implement of the conversion process of all currently available useful information to make effective solutions and ensure the functioning of a competitive logistics system.

The review and analysis of the methodological problems of the choice and decisionmaking theory in the management of the logistics process have identified the need to take into consideration the level of uncertainty. The development of these issues should be carried out on the basis of information and statistical methods and models of decision-making, taking into account the uncertainty and risks, with the construction of the adaptive forecasting models. Current advances do not allow solving these problems quite effectively. Since the methods of scientific, technical and economic analysis have specific features of their application, for example, for a multi-dimensional prediction parameter logistic systems, therefore there is a need for the informationstatistical approach.

The spread of the open innovation model implies not only an increase in the internationalization of the entrepreneurial sector. Initiated by transnational companies innovations can not only overcome institutional and disciplinary barriers, but also geographical. The issues of logistic development should be addressed within the framework of the open innovations ensuring the integration of key and supporting participants of supply chains based on open innovation interaction. The level of uncertainty is influenced by the fact that the use of only open innovations in the logistic system results in fewer stochastic factors in forecasting.

The research question of this paper is to propose the methodology of investment decisions on logistics (supply) chain modernization (design) in case of uncertainty based on information and statistical technologies.

\section{Methodology and findings}

A lot of work has been devoted to the design of logistics (supply) chain (Alonso-Ayuso et al, 2003; El Hannach et al, 2016b; Lim et al, 2017; Park et al, 2016; Pisani, 2004). Many researchers consider this problem from an economic point of view.

For example, Hämäläinen (2017) provides a literature overview on the key concepts of cost aggregation, multimodal transport, logistic chain and maritime transport.

Longo (2012) demonstrates the need to consider different sustainability aspects in supply chain redesign and optimization problems. To this end a simulation model of local pharmaceutical business retail is presented as application example. Three different sustainability aspects are considered (technical sustainability, economic sustainability and environmental sustainability) when investigating two different problems: the addition of new pharmacies to the supply chain and optimization of the supply chain routes.

Nagurney (2010) proposes a framework for supply chain network design and redesign that allows for the determination of the optimal levels of capacity and operational product flows associated with supply chain activities of manufacturing, storage, and distribution at minimal total cost and subject to the satisfaction of product demands.

Investment decisions on logistics (supply) chain modernization is generally an evaluation of the alternatives proposed for the investor based on the indicators and the 
selection of the projects according to the existing conditions (constraints). If possible, the multi-criteria problem usually reduces to a one-criterion issue by introducing a generalized criterion to simplify the problem (Khovanov, 2005). In our case, this criterion could be the generalized index of the investment project attractiveness.

For the convolution of partial indicators related to a particular investment project, it seems reasonable to use the method of the potential distribution of probability. An information situation exploiting this method is characterized by the fact that investors know only the data on the corresponding private characteristics of investment projects. In this case, it seems appropriate to put forward a hypothesis of a linear convolution of some partial dimensionless parameters (Khovanov, 2005; Garanin et al., 2015).

There is a sufficient number of different methods for determining the weights of such convolutions. They are all based on a particular behavior model of the social and economic systems, which is usually postulated informally. Meanwhile, a greater objectivity is typical of the models built using the principle of maximum uncertainty. One possible approach to evaluate these weights, which is based on this principle, is the method the potential distribution of probability. The content of this situation may be represented by the following scheme.

Let consider $n$ investment projects which, in their purpose and contents, are competitors in terms of investing funds for logistics (supply) chain modernization. Each of these projects is associated with a set of characteristics that define its investment attractiveness.

Let such characteristics be $\boldsymbol{m}$. Define $\boldsymbol{x}_{\boldsymbol{i} j}$ as particular indicators of comparable projects. Initial data in this case are conveniently situated in a matrix

$$
X=\left[\begin{array}{rrr}
x 11 & x 21 & x_{m 1} \\
x 12 & x 22 & x_{m 2} \\
x_{1 n} & x_{2 n} & x_{m n}
\end{array}\right]
$$

Weight of the $\boldsymbol{j}$-th characteristic in the distribution of funds to achieve the desired level of investment project efficiency is generally unknown. It is required to assess the weight of each characteristic in the distribution of resources taking into account the objectively existing uncertainties.

The principle of a potential distribution postulates an application of the Bayesian criterion as a comprehensive indicator for measuring the attractiveness of the project. It has the following form

$$
b_{i}=\sum_{j=1}^{m} p_{j} r_{i j}
$$

where $\boldsymbol{r}_{\boldsymbol{i}}$ - dimensionless parameters, $\boldsymbol{r}_{\boldsymbol{i}}=\boldsymbol{x}_{\boldsymbol{i}} / \boldsymbol{x}_{\boldsymbol{j}}$, if an increase in $\boldsymbol{x}_{\boldsymbol{i} \boldsymbol{j}}$ leads to growth of $\boldsymbol{b}$ and $\boldsymbol{r}_{i j}=\boldsymbol{x}_{\boldsymbol{j} j} / \boldsymbol{x}_{\boldsymbol{i}}$, if the increase in $\boldsymbol{x}_{i j}$ leads to the reduction of $\boldsymbol{b} ; \boldsymbol{x}_{\boldsymbol{j}}$ - characteristics of the standard, which is considered as one of the projects.

Then the weighting factors $\boldsymbol{p}_{\boldsymbol{j}}$ reflecting a pattern of environment behavior are found by maximizing the Shannon entropy (El Hannach et al., 2016a) 


$$
H=-\sum_{j=1}^{m} p_{j} \cdot \ln p_{j} \rightarrow \max
$$

under the constraints

$$
\sum_{j=1}^{m} p_{j}=1, \prod_{j=1}^{m} \bar{r}_{j}^{p_{j}}=\text { const }
$$

It can be shown that the expression for estimating weights in this case has the form

$$
p_{j}=\left(\sum_{i=1}^{n} r_{i j}\right)^{-1}\left[\sum_{j=1}^{m}\left(\sum_{i=1}^{n} r_{i j}\right)^{-1}\right]^{-1} .
$$

Constraints (3) postulate the normalization and constancy of the geometric mean. Physically, this means that the relative increase in the weight of the $j$-th characteristic is in proportion to the relative increment of the level of the same characteristic among the totality of the considered projects, and the proportionality coefficient depends on the level achieved.

Thus, by calculating with expression (4) the significance coefficients, it is possible not only to rank the private indicators on their contribution, but also to choose the most attractive project from the offered alternatives. The efficiency of the method is demonstrated in the following example. Initial data for five specific indicators of five alternative projects are shown in Table 1.

Reduced matrix of initial data, calculated by expressions (2), where the standard accepted is project 1 , is as follows:

$$
R=\left[\begin{array}{ccccc}
1 & 1.3 & 0.7 & 2.6 & 1.1 \\
1 & 1.25 & 1.08 & 1.42 & 0.83 \\
1 & 0.92 & 1.13 & 0.84 & 1.1 \\
1 & 0.67 & 1,44 & 0,78 & 1.1 \\
1 & 0.75 & 0.6 & 1 & 0.5
\end{array}\right]
$$

Then the matrix of calculated by expressions (1-4) integrated indicators of investment attractiveness of alternative projects equals

$$
B=\left[\begin{array}{lllll}
1 & 0.94 & 0,98 & 1.24 & 0.9
\end{array}\right] \text {. }
$$

The weighting coefficients for particular projects characteristics calculated by the expression (4) are summarized in Table 2.

Table 1 Characteristics of alternative investment projects

\begin{tabular}{llllll}
\hline Projects characteristics & Projects & & & \\
\cline { 2 - 6 } & 1 & 2 & 3 & 4 & 5 \\
\hline 1. Net Present Value (NPV), mIn. Rub. & 1 & 1.3 & 0.7 & 2.6 & 1.1 \\
2. Profitability Index (PI) & 1.2 & 1.5 & 1.3 & 1.7 & 1 \\
3. Internal Rate of Return (IRR), \% & 15.5 & 14.2 & 17.5 & 13 & 17 \\
4. Return on investment (ROI), \% & 45 & 30 & 65 & 35 & 50 \\
5. Payback period, years & 3 & 4 & 5 & 3 & 6 \\
\hline
\end{tabular}

Source: developed the authors 
Table 2 Importance (significance) of the characteristics

\begin{tabular}{ll}
\hline Projects characteristics & Coefficients \\
\hline 1. Net Present Value (NPV), mln. Rub. & 0.16 \\
2. Profitability Index (PI) & 0.18 \\
3. Internal Rate of Return (IRR), \% & 0.20 \\
4. Return on investment (ROI), \% & 0.20 \\
5. Payback period, years & 0.26 \\
\hline
\end{tabular}

Source: developed the authors

Analyzing the results of the calculations, we can conclude that the most attractive for the investor is project 4 , because it has the highest generalized index.

\section{Emphasis on the subjective evaluations of the importance of project characteristics}

Another conclusion that can be drawn on the basis of the initial data and the calculations is that the payback period is the defining characteristic of these projects is, and has the highest weighting factor. However, it makes sense to take into account the opinions and experience of qualified experts in the evaluation of the project characteristics importance. For this purpose, it is advisable to take into account the subjective opinion of experts in the formation of the matrix (5).

Typically, these problems are solved by estimates formation (usually in points) for all characteristics and then assigned weighting coefficients for characteristics in order to convolute them further into a generalized index. However, in this case, the problem, which is shown on the stage of grading, is to formalize the intuitive approach. The method based on the minimization of participation of experts' opinion should be recognized as a more objective method. This approach requires the expert to place a number of preferences for project characteristics, and weights are calculated using the principle of maximum uncertainty. It can be shown, that under these conditions, the most objective scale is Fishburn estimates (Fishburn, 1986)

$$
\widehat{p}_{j}=\frac{2(m-l+1)}{m(m+1)}, j=\overline{1, m}
$$

where $\boldsymbol{n}$ - number of estimated characteristics; $\boldsymbol{j}$ - rank in the scale of priorities for the $j$-th characteristic.

In other words, it suffice to place the data in order of importance (significance, impact, etc.) and to determine the weights by the expression (7). Then the results in Table 2 should be recalculated according to the subjective factor of the first order (the importance of the project characteristics). Continuing the example, we can assume that, in the opinion of experts, the prioritization of the relevant characteristics of the projects and the weights look like as shown in Table 3.

Then weighting factors for characteristics of the projects taking into consideration a subjective factor can be calculated by the expression

$$
Q_{j}=\gamma P_{\ni j}+(1-\gamma) P_{\Pi j}, j=\overline{1, m}
$$

where $\boldsymbol{\gamma}$ - the degree of trust to experts; $\boldsymbol{P}_{\boldsymbol{j}}$ - expert (subjective) assessment of the $\boldsymbol{j}$-th weighting factor; $\boldsymbol{P}_{\boldsymbol{n} \boldsymbol{j}}$ - potential (objective) assessment of the $\boldsymbol{j}$-th weighting factor; $\boldsymbol{n}$ number of estimated characteristics. 
Table 3 Subjective priority of characteristics

\begin{tabular}{lll}
\hline Projects characteristics & Priority & Coefficients \\
\hline 1. Net Present Value (NPV), mIn. Rub. & 4 & 0.13 \\
2. Profitability Index (PI) & 3 & 0.20 \\
3. Internal Rate of Return (IRR), \% & 5 & 0.07 \\
4. Return on investment (ROI), \% & 1 & 0.33 \\
5. Payback period, years & 2 & 0.27 \\
\hline
\end{tabular}

Source: developed the authors

The results of this recalculation with a 50\% level of confidence in expert opinions are summarized in Table 4. The analysis of the results indicates the sensitivity of the method to both an objective and a subjective factor (see Tables 2 and 4).

Changing $\gamma$ from no-confidence level (0\%) to absolute confidence level (100\%), we see the convergence of the results to the limits either for the purely objective or for the purely subjective assessment.

Emphasis on the experts' opinions in the evaluation of alternative investment projects So far, we have considered a problem of the subjective opinions of experts in assessing the significance of the projects characteristics. The second scale of the original Table 1 includes a list of projects. So, expert opinion must be formalized by taking into account the preferences among investment projects. According to the experts, projects are ranked in the order of preferences, and then with an expression similar to (7), weights reflecting the quantitative measure of preference are estimated (taking into account the subjective factor of the second order). With the problem being solved, let us assume that the evaluation by experts allowed to place the projects in the order of preferences, presented in Table 5. From the calculation results, summarized in Table 5, it is seen that the subjective evaluation given by the experts does not agree with the more objective and potential estimates. Thus, the generalized evaluation of investment attractiveness, calculated by the expression similar to (8), takes into account both of these factors.

Thus, the most preferred investment project is project 4 .

\section{Investigation of the effect of choice standard}

We have shown above that formalizing information situation of potential distribution of probability involves the formation of Bayesian criterion (1), to assess the weights of which we introduce the dimensionless parameters $\boldsymbol{r}_{\boldsymbol{i} \boldsymbol{j}}$. It uses the concept of a

Table 4 Generalized evaluation of the characteristics importance

\begin{tabular}{ll}
\hline Projects characteristics & Coefficients \\
\hline 1. Net Present Value (NPV), mIn. Rub. & 0.14 \\
2. Profitability Index (PI) & 0.19 \\
3. Internal Rate of Return (IRR), \% & 0.13 \\
4. Return on investment (ROI), \% & 0.27 \\
5. Payback period, years & 0.27 \\
\hline
\end{tabular}

Source: developed the authors 
Table 5 Expert opinion in the evaluation of projects preference

\begin{tabular}{llllll}
\hline Parameters & \multicolumn{3}{l}{ Projects } & & \\
\cline { 2 - 7 } & 1 & 2 & 3 & 4 & 5 \\
\hline Project priority & 2 & 1 & 4 & 5 & 3 \\
Assessment of the "weight" of preferences & 0.27 & 0.33 & 0.13 & 0.07 & 0.2 \\
"Potential assessment" (6) & 1 & 0.94 & 0.98 & 1.24 & 0.9 \\
Generalized assessment of investment attractiveness & 0.64 & 0.64 & 0.56 & 0.66 & 0.55 \\
\hline
\end{tabular}

Source: developed the authors

"standard", and each of the projects can be considered as such. In fact, it is necessary to consider the following feature of this method.

Let us apply the abstract matrix $X$ that contains $\boldsymbol{m}$ specific indicators (characteristics) of some $\boldsymbol{n}$ comparable projects in Table 6 .

To go to the dimensionless matrix of indicators, we use the expression $\boldsymbol{r}_{\boldsymbol{i j}}=\boldsymbol{x}_{\boldsymbol{i} \boldsymbol{j}} / \boldsymbol{x}_{\boldsymbol{b} \boldsymbol{j}}$ in formula (1). The following Table 7 presents input data in case project 1 is selected as a standard (basic project).

The use of the expression (4) when selecting project 1 as the basic one (standard) gives the following values of weights.

$$
P^{(1)}=\left[\begin{array}{lllll}
0.07 & 0.17 & 0.17 & 0.23 & 0.36
\end{array}\right]^{T} \text {. }
$$

Similarly, the weights are calculated when selecting project $2,3, \ldots$ as a standard.

$$
\begin{aligned}
& P^{(2)}=\left[\begin{array}{lllll}
0.17 & 0.14 & 0.08 & 0.25 & 0.36
\end{array}\right]^{T} ; \\
& P^{(3)}=\left[\begin{array}{lllll}
0.13 & 0.35 & 0.24 & 0.20 & 0.08
\end{array}\right]^{T} ; \\
& P^{(4)}=\left[\begin{array}{lllll}
0.28 & 0.22 & 0.23 & 0.21 & 0.06
\end{array}\right]^{T} ; \\
& P^{(5)}=\left[\begin{array}{lllll}
0.27 & 0.14 & 0.25 & 0.13 & 0.21
\end{array}\right]^{T} .
\end{aligned}
$$

Analyzing the results, it must be admitted that the choice of the project as the base one affects the weighting factors of their characteristics. In other words, the weight of the private indicator in the complex characteristic of the project is highly dependent on the choice of the base object for comparison. Since the weighting factors are only for internal operations, their use for other purposes ignoring this method is incorrect. Let us consider the effect of the base project selection on a generalized indicator (1). To do this, using the above-mentioned weight $\boldsymbol{P}_{\boldsymbol{j}}$, we calculate the value of the indicator (1) for the different cases of base project selection:

$$
\begin{aligned}
& b^{(1)}=\left[\begin{array}{lllll}
1.00 & 1.27 & 1.17 & 1.56 & 1.79
\end{array}\right] ; \\
& b^{(2)}=\left[\begin{array}{lllll}
0.79 & 1.00 & 0.92 & 1.22 & 1.41
\end{array}\right] ;
\end{aligned}
$$

Table 6 Initial data for investigation

\begin{tabular}{llllll}
\hline Characteristics & Projects (i) & & & \\
\cline { 2 - 6 } & 1 & 2 & 3 & 4 & 5 \\
\hline 1 & 11 & 34 & 24 & 67 & 76 \\
2 & 23 & 23 & 54 & 46 & 34 \\
3 & 21 & 12 & 34 & 45 & 56 \\
4 & 23 & 32 & 23 & 32 & 23 \\
5 & 43 & 56 & 12 & 11 & 44 \\
\hline Source: developed the authors & & & &
\end{tabular}


Table 7 Input data (project 1 - basic one)

\begin{tabular}{llllll}
\hline $\begin{array}{l}\text { Characteristics } \\
\text { (j) }\end{array}$ & \multicolumn{5}{l}{ Projects (i) } \\
\cline { 2 - 6 } & 1 & 2 & 3 & 4 & 5 \\
\hline 1 & 1 & 3.09 & 2.18 & 6.09 & 6.90 \\
2 & 1 & 1.00 & 2.34 & 2.00 & 1.47 \\
3 & 1 & 0.57 & 1.61 & 2.14 & 2.66 \\
4 & 1 & 1.39 & 1.00 & 1.39 & 1.00 \\
5 & 1 & 1.30 & 0.27 & 0.25 & 1.02 \\
\hline
\end{tabular}

Source: developed the authors

$$
\begin{aligned}
b^{(3)} & =\left[\begin{array}{lllll}
0.86 & 1.09 & 1.00 & 1.33 & 1.53
\end{array}\right] ; \\
b^{(4)} & =\left[\begin{array}{lllll}
0.64 & 0.82 & 0.75 & 1.00 & 1.15
\end{array}\right] ; \\
b^{(5)} & =\left[\begin{array}{lllll}
0.56 & 0.71 & 0.65 & 0.87 & 1.00
\end{array}\right] .
\end{aligned}
$$

The comparison $\boldsymbol{b}^{(i)}$ shows that the selection of the base project also strongly affects the absolute values of the generalized indicator. Therefore, values can be used only for comparison on a «better or worse» principle in the formation of a number of preferences for the projects under consideration. Thus, it is easy to see that, in all cases, when selecting the basic project, a number of preferences remains identical: 5, 4, $2,3,1$, despite the fact that the absolute values vary significantly in case the basic project changes.

Research limitations/implications Thus, the potential distribution of probability can be successfully used for the qualitative comparison of a number of projects in the form of preferences. The quantitative evaluation of both weights and generalized indicators calculated by this method is relative and strongly depends on the choice of the base project.

The proposed approach enables the integration of previously developed procedures for statistical analysis of data, and implemented in the form of program information processing technologies with methods of decision-making support based on maximum uncertainty principle. In this case, a multi-dimensional prediction of the logistic system parameters can be represented in the form of branched algorithm, which is based on well-known methods of different types of analysis such as correlation, time series, factorial and mathematical analysis. At the same time, increase of the objectivity and validity of the results is ensured not only by the implementation of the consistency principles, but also by the introduction of a comprehensive verification of the forecast results of the procedure. Automation of this kind of algorithms allows improving decision support system and thereby contributing to the adequate and efficient management of logistics systems.

Acknowledgements

Not applicable

Funding

Not applicable 
Authors' contributions

NL. Data collection, calculation and approbation of the approach, methodology development. AS. Conclusions, critical view and translation of the article. DG. Methodology development. All authors read and approved the final manuscript.

\section{Competing interests}

The authors declare that they have no competing interests.

\section{Publisher's Note}

Springer Nature remains neutral with regard to jurisdictional claims in published maps and institutional affiliations.

\section{Author details}

${ }^{1}$ Peter the Great St. Petersburg Polytechnic University, St. Petersburg, Russia. ${ }^{2}$ Chistopol autonomous campus, Kazan National Research Technical University, Kazan, Russia.

Received: 31 October 2017 Accepted: 10 January 2018

Published online: 29 January 2018

\section{References}

Alonso-Ayuso, A., Escudero, L., Garín, A. et al. (2003). An approach for strategic supply chain planning under uncertainty based on stochastic 0-1 programming. Journal of Global Optimization 26, $97 \mathrm{https}: / /$ doi.org/10.1023/A: 1023071216923

El Hannach D, Marghoubi R, Dahchour M. (2016a). Project portfolio management towards a new project prioritization process, Information Technology for Organizations Development (IT4OD). pp. 1-8.

El Hannach D, Marghoubi R, Dahchour M. (2016b). Project portfolio management information systems (PPMIS) information entropy based approach to prioritize PPMIS", Information Science and Technology (CiSt). 4th IEEE International Colloquium, pp. 228-234.

Fishburn P. C. (1986). The axioms of subjective probability. Stat. Sci.. V.1. No. 3

Garanin D., Pervuhin D., Shpenst V. (2015). Bases of Stochastic Similarity of Difficult Systems. Applied methods of statistical analysis. Novosibirsk. pp. 343-350.

Hämäläinen, E., Twrdy, E., \& Inkinen, T. (2017). Cost aggregation in export logistics chain. Journal of Open Innovation: Technology, Market, and Complexity, 3, 26 https://doi.org/10.1186/s40852-017-0077-9

Khovanov, N.V. (2005). Evaluation of complex economic systems and processes under uncertainty. On the 95th anniversary of the method of Krylov's aggregates. Vestneyk SPbGU. No. 1, pp. 138-144.

Lim, D., Moon, Y., Kim, K., \& Lee, H. (2017). Methodology for searching and allocating Enterprises in the Supply Chain by using the business information database and trademark rights database. Science, Technology and Society, 22(3), 524538 https://doi.org/10.1177/0971721817724317

Longo, F. (2012). Sustainable supply chain design: An application example in local business retail. SIMULATION, 88(12), 1484-1498 https://doi.org/10.1177/0037549712458983

Nagurney, A. (2010). Optimal supply chain network design and redesign at minimal total cost and with demand satisfaction. International Journal of Production Economics, 128(1), 200-208.

Park, J. H., Lee, B., Moon, Y. H., et al. (2016). Study for selection of industrial areas suitable to small and medium-sized enterprises (SMEs) in Korea. Journal of Open Innovation: Technology, Market, and Complexity, 2, 19 https://doi.org/10. 1186/s40852-016-0045-9

Pisani, J. (2004). Optimising supply chain investments - An integrated approach. Journal of Generic Medicines, 1(3), 242248 https://doi.org/10.1057/palgrave.jgm.4940028

\section{Submit your manuscript to a SpringerOpen ${ }^{\circ}$ journal and benefit from:}

- Convenient online submission

- Rigorous peer review

- Open access: articles freely available online

- High visibility within the field

- Retaining the copyright to your article 